\title{
Laboratory device for the evaluation of selective vegetal fibres
}

\author{
Valérie Lempereur ${ }^{1}$, Michel Reynolds² ${ }^{2}$ Carole Koestel $^{2}$, Magali Grinbaum ${ }^{3}$, François Davaux ${ }^{4}$, Céline Louaisil ${ }^{5}$, \\ and Johannes Rösti ${ }^{2}$ a \\ ${ }^{1}$ Institut Français de la Vigne et du Vin (IFV), 210 boulevard Vermorel, CS60320, 69661 Villefranche s/Saône, France \\ ${ }^{2}$ Agroscope, Route de Duiller 50, CP. 1012, 1260 Nyon, Switzerland \\ ${ }^{3}$ Institut Français de la Vigne et du Vin (IFV), Institut Rhodanien, 2260 Route de Gres, 84100 Orange, France \\ ${ }^{4}$ Institut Français de la Vigne et du Vin (IFV), V'innopole, Brame-Aïgues, BP. 22, 81310 Lisle sur Tarn, France \\ ${ }^{5}$ REALDYME, ZA Diepe, 28700 Garancières en Beauce, France
}

\begin{abstract}
Protection of the vineyard against diseases and pests may lead to pesticide residues in the wine. Traces of these active substances, even at concentrations below the legal limits, alarm the consumers and can compromise the potential to sale wines to some markets. A new oenological practice based on the use of selective vegetal fibres for the reduction of pesticide residues in wine is under evaluation by the International Organization of Vine and Wine. This technology, implemented on wine during filtration, is very effective for certain substances and impacts only little the wine quality. A laboratory pilot filtration device has been developed in order to confirm the efficiency of this treatment and its impact on the wine quality before its large-scale use in industrial conditions. This simple device is made of a peristaltic pump and a laboratory filter holder. Several wines with different fibre doses and filtration speeds can be rapidly tested, at bottle scale $(75 \mathrm{cl})$. This pilot filtration device would be a quick and easy tool for the winemakers to evaluate the impact of a filtration on their wines using selective vegetal fibres in terms of efficiency to reduce the pesticide residues, chemical composition and of sensory quality.
\end{abstract}

\section{Introduction}

Protection of the vineyard against diseases and pests may lead to pesticide residues in the wine. In its report on pesticides residues in food, the European Food Safety Authority showed that $49 \%$ of the 941 wines analysed in 2013 contained one or more detectable residues [1]. Traces of these active substances, even at concentrations below the legal limits, alarm the consumers and can compromise the potential to sale wines to some markets. The only oenological practice authorized by the International Organization of Vine and Wine (OIV) to reduce the level of pesticides is the treatment with carbon, in addition to musts [2]. In its strategic plan, OIV recommends to contribute to the safety of the consumers and to consider their expectations, especially to propose guidelines for the detection and reduction of contaminations in vitivinicultural practices, processes and treatments [3].

A new oenological practice based on the use of selective vegetal fibres for the reduction of pesticide residues in wine is under evaluation by OIV. This technology, implemented in wine during filtration, is very effective for certain substances and impacts only little the wine quality [4]. The functional principle is based on a physical phenomenon of adsorption of contaminants present in wine. Selective vegetal fibres must be used on wines complying with the legal requirements and the

\footnotetext{
a e-mail: johannes.roesti@agroscope.admin.ch
}

related pesticide limits. This practice is recommended in addition to good vine-growing practices.

The use of selective vegetal fibres has been tested at wine stage. Several trials have been carried out at industrial scale and showed an interesting reduction of pesticide residues in wine [4]. However, as this represents a new oenological practice, winemakers need precise and individual information about the effects of selective vegetal fibres in terms of pesticide removal and impact on the chemical and sensory composition of their wine. We therefore decided to develop a laboratory device to simulate the filtration with selective vegetal fibres at bottle scale. This device should be easy and quick to use and simulate the application at large scale. In order to be accessible for a basic oenological laboratories, the device was developed starting from equipment and parts already present in laboratories, such as those used to measure the filterability of wines, called clogging index.

This article presents the description of the device, the first tests carried out with it and the results obtained. It is the result of a collaborative work between Agroscope who optimized the device and made the trials, IFV who designed the device and analyzed the pesticides, and Realdyme who produced the fibres and gave advice about their use.

\section{Materials and methods}

\subsection{Laboratory pilot filtration device}

The laboratory pilot filtration device was developed in order to test the impact of a treatment of wines with 
Table 1. Residues of seven spiked fungicides in white wine and after filtration with the laboratory pilot device containing kieselguhr or a mix of selective vegetal fibres $(0.73 \mathrm{~g})$ and kieselguhr. The wines for the measurement of the spiking recovery rate and the filtration trials were prepared independently. The measured values are means of three repetitions and the errors indicate the confidence interval at $95 \%$. The reduction rate is calculated as the ratio between the values for the filtration with selective fibres and the filtration with kieselguhr. Asterisks indicate a significant difference from the values before filtration $(\alpha=5 \%)$. Measured values below the detection limit (in brackets) are indicated with nd.

\begin{tabular}{|c|c|c|c|c|c|c|}
\hline & $\begin{array}{c}\text { target spiking } \\
{[\mu \mathrm{g} / \mathrm{L}]}\end{array}$ & $\begin{array}{c}\text { measurement } \\
\text { spiking }[\mu \mathrm{g} / \mathrm{L}]\end{array}$ & $\begin{array}{c}\text { recovery } \\
\text { rate }[\%]\end{array}$ & $\begin{array}{c}\text { measurement after filtration } \\
\text { kieselguhr }[\mu \mathrm{g} / \mathrm{L}]\end{array}$ & $\begin{array}{c}\text { measurement after filtration } \\
\text { selective fibres }[\mu \mathrm{g} / \mathrm{L}]\end{array}$ & $\begin{array}{c}\text { reduction } \\
\text { rate }[\%]\end{array}$ \\
\hline Mandipropamid & 60 & $68 \pm 12$ & 13 & $42 \pm 5$ & nd $(<2.0)$ & 100 \\
\hline Iprovalicarb & 60 & $52 \pm 11$ & 87 & $49 \pm 1$ & $35 \pm 1^{*}$ & 33 \\
\hline Quinoxyfen & 60 & $4 \pm 1$ & 7 & $4 \pm 0$ & nd $(<0.3)$ & 100 \\
\hline Cyprodinil & 60 & $41 \pm 9$ & 68 & $50 \pm 4$ & nd $(<0.3)$ & 100 \\
\hline Fludioxonil & 60 & $11 \pm 8$ & 18 & $15 \pm 4$ & $\mathrm{nd}(<1.0)$ & 100 \\
\hline Fenpropidin & 60 & $48 \pm 10$ & 80 & $50 \pm 1$ & $20 \pm 6^{*}$ & 60 \\
\hline Fluopyram & 60 & $59 \pm 11$ & 98 & $63 \pm 5$ & & 66 \\
\hline
\end{tabular}

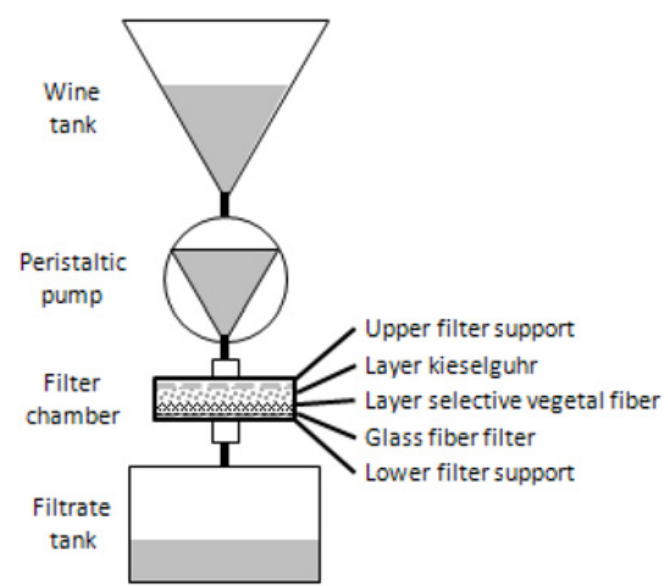

Figure 1. Schematic view of the laboratory pilot filter device.

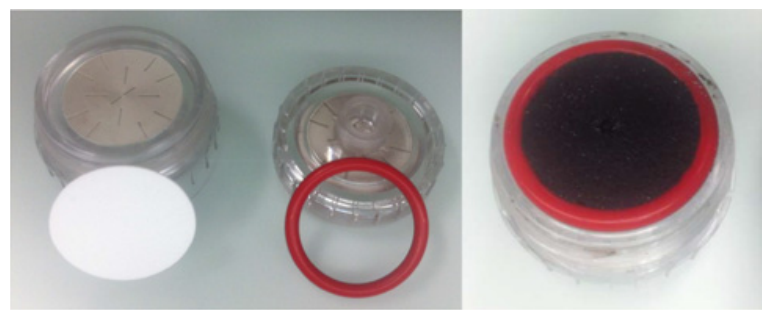

Figure 2. Detailed pictures of the filter chamber. Left: empty with lower filter support and glass-fiber filter. Middle: empty with upper filter support and rubber seal. Right: open and filled with selective vegetal fibres.

selective vegetal fibres at bottle scale $(75-100 \mathrm{cl})$. The heart of the device consists of the filtration chamber (Fig. 1, Fig. 2), Sartorius polycarbonate filter holder, diameter $50 \mathrm{~mm}$ (\#16508). The filter holder contains a filter support at the bottom that was covered by a Millipore AP25 glass-fiber filter, diameter $47 \mathrm{~mm}$, in order to support the filtration cake. At the top, the filter holder contains another filter support that allows even distribution of the liquid flow in the filtration chamber. A rubber seal contains the filtration cake laterally and allows tight closure of the filtration chamber. The available surface area for filtration is $12.6 \mathrm{~cm}^{2}$ and the available volume for the filtration cake is $5.0 \mathrm{ml}$. The liquid flow through the filtration chamber was driven by a peristaltic pump (DOSE IT, Integra Biosciences, Zizers, Switzerland) using tubing
Table 2. Technical parameters of filtrations with the laboratory pilot device containing kieselguhr or a mix of selective vegetal fibres $(0.73 \mathrm{~g})$ and kieselguhr. The indicated values are means of three repetitions and the errors indicate the confidence interval at $95 \%$. Asterisks indicate a significant difference between the filtrations $(\alpha=5 \%)$.

\begin{tabular}{|c|c|c|c|}
\hline & & $\begin{array}{c}\text { filtration } \\
\text { kieselguhr }\end{array}$ & $\begin{array}{c}\text { filtration } \\
\text { selective fibres }\end{array}$ \\
\hline Pump flow rate & {$[\mathrm{L} / \mathrm{h}]$} & $0.84 \pm 0.06^{*}$ & $0.73 \pm 0.09^{*}$ \\
\hline Filtration flow rate & {$\left[\mathrm{L} / \mathrm{h} / \mathrm{m}^{2}\right]$} & $672 \pm 44^{*}$ & $582 \pm 71^{*}$ \\
\hline Temperature entry & {$\left[{ }^{\circ} \mathrm{C}\right]$} & $22 \pm 1$ & $22 \pm 1$ \\
\hline Temperature exit & {$\left[{ }^{\circ} \mathrm{C}\right]$} & $22 \pm 1$ & $22 \pm 0$ \\
\hline Turbidity entry & {$[\mathrm{NTU}]$} & $0.9 \pm 0.1$ & $0.9 \pm 0.1$ \\
\hline Turbidity exit & {$[\mathrm{NTU}]$} & $1.0 \pm 0.1$ & $0.9 \pm 0.1$ \\
\hline
\end{tabular}

with $4 \mathrm{~mm}$ inner diameter allowing a flow range between 8.4-837 ml/min (Fig. 1). Upstream a conical tank holding at least $100 \mathrm{cl}$ of wine was connected to the pump and downstream, a filtrate tank holding the same amount was connected to the filtration chamber using tubing with $8 \mathrm{~mm}$ inner diameter (Fig. 1).

The filter chamber was filled with layers of selective vegetal fibres (Realdyme, Garancières-en-Beauce, France) and kieselguhr (Clarcel Flo 2A, Ceca, France) or a mixture of both. In order to achieve this goal, the desired amount of selective vegetal fibres or kieselguhr was mixed in $500 \mathrm{ml}$ of deionized water for about $5 \mathrm{~min}$. The slurry was then pumped through the filtration chamber at a speed of $400 \mathrm{ml} / \mathrm{min}$. It is recommended to deposit a layer with the desired amount of selective vegetal fibres first followed by kieselguhr in order to fill the filtration chamber completely. This allows a stable positioning of the filtration cake between the upper and lower filter support and any surplus kieselguhr can be discarded.

For operations, the desired amount of wine was poured into the tank and the connection tubing was filled with the wine at medium pump speed. The tubing was then connected to the filtration chamber and the wine was pumped through the filtration cake at low speed $(14.3 \mathrm{ml} / \mathrm{min})$. The first $50 \mathrm{ml}$ of filtrate were discarded. The remainder of the filtrate was collected in the filtrate tank before analysis.

In order to evaluate the repeatability of the device each control and treatment trial was carried out in triplicate. 
Table 3. Residues of five fungicides used in the vineyard, measured in red wine before and after filtration with the laboratory pilot device containing three different amounts of selective vegetal fibres $(0.16 \mathrm{~g}, 0.33 \mathrm{~g}, 0.66 \mathrm{~g})$. The measured values are means of three repetitions and the errors indicate the confidence interval at $95 \%$. The reduction rate is calculated as the ratio between the measured values after and before filtration. Letters indicate significantly different groups of mean values $(\alpha=5 \%)$.

\begin{tabular}{|c|c|c|c|c|c|c|c|}
\hline & $\begin{array}{c}\text { measurement before } \\
\text { before filtration } \\
{[\mu \mathrm{g} / \mathrm{L}]}\end{array}$ & $\begin{array}{c}\text { measurement } \\
\text { filtration selective } \\
\text { fibres } 0.16 \mathrm{~g}[\mu \mathrm{g} / \mathrm{L}]\end{array}$ & $\begin{array}{c}\text { reduction } \\
\text { rate [\%] }\end{array}$ & $\begin{array}{c}\text { measurement after } \\
\text { filtration selective } \\
\text { fibres } 0.33 \mathrm{~g}[\mu \mathrm{g} / \mathrm{L}]\end{array}$ & $\begin{array}{c}\text { reduction } \\
\text { rate [\%] }\end{array}$ & $\begin{array}{c}\text { measurement after } \\
\text { filtration selective } \\
\text { fibres } 0.66 \mathrm{~g}[\mu \mathrm{g} / \mathrm{L}]\end{array}$ & $\begin{array}{c}\text { reduction } \\
\text { rate [\%] }\end{array}$ \\
\hline Cyprodinil & $37 \pm 1^{\mathrm{a}}$ & $21 \pm 2^{\mathrm{b}}$ & 43 & $14 \pm 3^{\mathrm{c}}$ & 62 & $5 \pm 1^{\mathrm{d}}$ & 86 \\
\hline Fenhexamid & $339 \pm 16$ & $436 \pm 173$ & na & $460 \pm 167$ & na & $329 \pm 68$ & na \\
\hline Fenpropidin & $90 \pm 5^{\mathrm{a}}$ & $74 \pm 5^{\mathrm{b}}$ & 18 & $57 \pm 7^{\mathrm{c}}$ & 37 & $29 \pm 6^{\mathrm{d}}$ & 68 \\
\hline Fludioxonil & $32 \pm 14^{\mathrm{a}}$ & $28 \pm 14^{\mathrm{a}}$ & na & $27 \pm 9^{\mathrm{ab}}$ & 16 & $16 \pm 8^{\mathrm{b}}$ & 50 \\
\hline Iprovalicarb & $16 \pm 1$ & $16 \pm 4$ & na & $16 \pm 4$ & na & $15 \pm 6$ & na \\
\hline
\end{tabular}

Table 4. Technical parameters of filtrations with the laboratory pilot device containing three different amounts of selective vegetal fibres $(0.16 \mathrm{~g}, 0.33 \mathrm{~g}, 0.66 \mathrm{~g})$. The indicated values are means of three repetitions and the errors indicate the confidence interval at $95 \%$.

\begin{tabular}{|l|c|c|c|c|}
\hline \multicolumn{1}{|c|}{ parameters } & units & $\begin{array}{c}\text { filtration } \\
\text { selective } \\
\text { fibres } 0.16 \mathrm{~g}\end{array}$ & $\begin{array}{c}\text { filtration } \\
\text { selective } \\
\text { fibres } 0.33 \mathrm{~g}\end{array}$ & $\begin{array}{c}\text { filtration } \\
\text { selective } \\
\text { fibres } 0.66 \mathrm{~g}\end{array}$ \\
\hline Pump flow rate & {$[\mathrm{L} / \mathrm{h}]$} & $0.84 \pm 0.05$ & $0.77 \pm 0.25$ & $0.83 \pm 0.04$ \\
\hline Filtration flow rate & {$\left[\mathrm{L} / \mathrm{h} / \mathrm{m}^{2}\right]$} & $668 \pm 38$ & $610 \pm 199$ & $662 \pm 30$ \\
\hline Temperature entry & {$\left[{ }^{\circ} \mathrm{C}\right]$} & $18 \pm 0$ & $18 \pm 1$ & $18 \pm 0$ \\
\hline Temperature exit & {$\left[{ }^{\circ} \mathrm{C}\right]$} & $22 \pm 1$ & $22 \pm 1$ & $21 \pm 1$ \\
\hline Turbidity entry & {$[\mathrm{NTU}]$} & $5.5 \pm 2.0$ & $5.2 \pm 3.1$ & $5.6 \pm 2.6$ \\
\hline Turbidity exit & {$[\mathrm{NTU}]$} & $1.8 \pm 0.0$ & $1.8 \pm 0.0$ & $1.8 \pm 0.0$ \\
\hline
\end{tabular}

\subsection{Wine samples and pesticide spiking}

The white wine was produced from cultivar Chasselas, PDO Morges (Switzerland) under strict organic guidelines. No pesticide residues could be detected (results not shown). Samples of this wine were then spiked with the following pesticides: Mandipropamid, Iprovalicarb, Quinoxyfen, Cyprodinil, Fludioxonil, Fenpropidin, and Fluopyram (all analytical grade, Sigma, USA). Pesticides were dissolved at $1 \mathrm{mg} / \mathrm{ml}$ in acetone and then diluted to $0.1 \mathrm{mg} / \mathrm{ml}$ in a model wine (distilled water with $12 \%$ ethanol, $\mathrm{pH} 3.2$, and $2 \mathrm{~g} / \mathrm{l}$ tartaric acid) before spiking the wine at a final concentration of $60 \mu \mathrm{g} / \mathrm{l}$. Except for Quinoxyfen, which was spiked directly from the acetone solution.

The red wine was produced from several cultivars Gamay, Pinot Noir, Merlot, Galotta, and Divico, PDO Lavaux (Switzerland) using synthetic fungicides for plant protection.

\subsection{Pesticide analysis}

Multi-residues analysis was realized on wine before and after filtration. The sample was extracted using the Quick, Easy, Cheap, Effective, Rugged and Safe (QuEChERS) method [5]. Extracts were analyzed by UPLC/MS/MS (Waters Acquity UPLC connected to a Waters Acquity TQD tandem mass spectrometer) [5]. The quantification was made by external calibration. Limits of Quantification (LQ) and Limits of detection (LD) are 1 and $0.3 \mu \mathrm{g} / \mathrm{L}$ unless specified otherwise.

\subsection{Color analysis and phenolic composition}

Color intensity was measured as the sum of the optical densities at 420,520, and $620 \mathrm{~nm}$. Color hue was measured as the ration between the optical densities at $420 \mathrm{~nm}$ and
$520 \mathrm{~nm}$. Total phenolics were measured as optical density at $280 \mathrm{~nm}$. Anthocyanins were measured as optical density at $520 \mathrm{~nm}$ after dilution in $1 \%(\mathrm{~m} / \mathrm{v}) \mathrm{HCl}$ and expressed as [mg/l] malvidine-3-glucoside using a conversion factor of 28.25 .

\subsection{Sensory analysis}

Wines were analyzed by a trained expert panel (10 participants) using a descriptive profile using 19 descriptors for aspect, aroma and taste. Some descriptors such as "Aroma quality", "Tannin quality" and "General quality" were hedonic. All others descriptors were objective. The experimental repeats were presented as three separate blocs within one tasting session. Each bloc contained one wine of each of the filtrations with the three different amounts of selective vegetal fibres. Assessment between the three wines of each bloc could be done comparatively.

\section{Results}

In order to test the repeatable efficiency of the laboratory pilot filter device, a first trial was carried out with a white wine spiked with seven different fungicides commonly used in Swiss viticulture. Although all seven compounds were added at a target concentration of $60 \mu \mathrm{g} / \mathrm{l}$, recovery rates of the residue analysis varied strongly (Table 1). Five out of the seven compounds showed a recovery rate close to the target ranging from $68 \%$ to $98 \%$. But Fludioxonil and Quinoxyfen could only be recovered at $18 \%$ and $7 \%$, respectively.

Regardless of the variable recovery rates, samples of $375 \mathrm{ml}$ of white wine were spiked in the same way and filtered with the laboratory pilot filter device either containing only kieselguhr as a negative control or a mix of selective vegetal fibres $(0.73 \mathrm{~g})$ and kieselguhr. The filtration was conducted at relatively low speed in order to get an estimated contact time of the wine with the selective vegetal fibres of about 15 seconds.

The technical parameters of the filtration such as flow rate, temperature, and turbidity could be kept quite stable throughout the three repetitions of each trial and between trials (Table 2). Despite a constant speed of the peristaltic pump the selective vegetal fibre seemed to reduce flow rate significantly over kieselguhr alone by $13 \%$.

The efficiency of the selective vegetal fibres for fungicide residue removal in this filtration trial was very high compared to the values obtained after filtration with kieselguhr alone (Table 1). Five out of the seven spiked compounds were removed below their detection limit. Iprovalicarb and Fluopyram showed lower reduction 
Table 5. Color and phenolic composition of the red wines before and after filtration with the laboratory pilot device containing three different amounts of selective vegetal fibres $(0.16 \mathrm{~g}, 0.33 \mathrm{~g}, 0.66 \mathrm{~g})$. The measured values are means of three repetitions and the errors indicate the confidence interval at $95 \%$. Letters indicate significantly different groups of mean values $(\alpha=5 \%)$.

\begin{tabular}{|c|c|c|c|c|}
\hline & before filtration & $\begin{array}{c}\text { after filtration selective } \\
\text { fibres } 0.16 \mathrm{~g}\end{array}$ & $\begin{array}{c}\text { after filtration selective } \\
\text { fibres } 0.33 \mathrm{~g}\end{array}$ & $\begin{array}{c}\text { after filtration selective } \\
\text { fibres } 0.66 \mathrm{~g}\end{array}$ \\
\hline Color intensity & $6.24 \pm 0.05^{\mathrm{bc}}$ & $6.37 \pm 0.15^{\mathrm{a}}$ & $6.28 \pm 0.08^{\mathrm{ab}}$ & $6.12 \pm 0.16^{\mathrm{c}}$ \\
\hline Color hue & $0.73 \pm 0.00^{\mathrm{a}}$ & $0.71 \pm 0.01^{\mathrm{b}}$ & $0.71 \pm 0.00^{\mathrm{b}}$ & $0.71 \pm 0.01^{\mathrm{b}}$ \\
\hline Total polyphenolic index & $43.68 \pm 0.11^{\mathrm{a}}$ & $43.53 \pm 0.16^{\mathrm{a}}$ & $43.50 \pm 0.16^{\mathrm{a}}$ & $43.06 \pm 0.27^{\mathrm{b}}$ \\
\hline Anthocyanins [mg/l] & $516.7 \pm 2.9^{\mathrm{a}}$ & $513.3 \pm 1.4^{\mathrm{ab}}$ & $514.3 \pm 7.6^{\mathrm{a}}$ & $507.3 \pm 10.0^{\mathrm{b}}$ \\
\hline
\end{tabular}

rates of $35 \%$ and $20 \%$, respectively. The reduction efficiencies show very little variability, proving the excellent repeatability of the laboratory pilot filter device for this kind of trial.

To further demonstrate the usefulness of the laboratory pilot filtration device to test the effects of selective vegetal fibres in terms of pesticide removal and impact on the chemical and sensory composition of the treated wine, a second trial on a red wine containing five residues of fungicides used the vineyard was performed (Table 3). Fenhexamid, an anti-botrytis, was found at the highest concentration of $339 \mu \mathrm{g} / \mathrm{l}$. The other compounds ranged between 16 and $90 \mu \mathrm{g} / \mathrm{l}$.

One liter of this red wine was filtered with the laboratory pilot device containing three different amounts of selective vegetal fibres $(0.16 \mathrm{~g}, 0.33 \mathrm{~g}$, and $0.66 \mathrm{~g})$. The fibres were deposited as a thin layer covered with kieselguhr in order to fill the filtration chamber. The technical parameters of the filtration such as flow rate, temperature, and turbidity could be kept stable throughout the three repetitions of each trial and between trials (Table 4). The filtration was conducted at relatively low speed. Nevertheless the contact time of the wine with the selective vegetal fibres was estimated to only 2, 6, and 9 seconds, respectively due to thin layers of fibres. As the red wine had not yet been filtered for bottling, its turbidity was at about 5.5 NTU. In each case the laboratory pilot filtration cleared the wine to 1.8 NTU.

The efficiency of the selective vegetal fibres for fungicide residue removal in this trial showed a differential behavior for the five active compounds (Table 3). Fenhexamid and Iprovalicarb were not removed by any of the three amounts of selective fibres. The other three compounds showed increasing reduction rates correlating with increasing amounts of selective fibres. The highest reduction at $86 \%$ was obtained for Cyprodinil when filtered with $0.66 \mathrm{~g}$ of selective fibres.

As it has been suggested that selective vegetal fibres might absorb phenolic compounds [4], the red wines filtered with the laboratory pilot device were analyzed chemically (Table 5). The measured values show indeed a slight reduction of color intensity, total polyphenolic index, and anthocyanins especially for the highest amount of selective fibres. Similarly, a sensory description of the red wines was performed. However, no significant impact could be detected between the three different amounts of selective fibres used. Even the descriptor "Aroma paper" linked to the aroma of selective vegetal fibres, on which the panel was specially trained, showed no significant trend. Nevertheless, by far the lowest p-values $(\sim 15 \%)$ were obtained for the descriptors "Color intensity" and "Tannin intensity" for the highest amount of selective fibres used indicating that some judges have
Table 6. Sensory attributes of the red wines before and after filtration with the laboratory pilot device containing three different amounts of selective vegetal fibres $(0.16 \mathrm{~g}, 0.33 \mathrm{~g}$, $0.66 \mathrm{~g}$ ). The measured values are means of three repetitions and the errors indicate the confidence interval at $95 \%$. Values range from 1 (absent/bad) to 7 (high/excellent).

\begin{tabular}{|l|c|c|c|}
\hline & $\begin{array}{c}\text { after filtration } \\
\text { selective } \\
\text { fibres 0.16g }\end{array}$ & $\begin{array}{c}\text { after filtration } \\
\text { selective } \\
\text { fibres 0.33g }\end{array}$ & $\begin{array}{c}\text { after filtration } \\
\text { selective } \\
\text { fibres 0.66g }\end{array}$ \\
\hline Color intensity & $4.91 \pm 0.13$ & $4.92 \pm 0.18$ & $4.86 \pm 0.08$ \\
\hline Aroma fruity & $4.32 \pm 0.22$ & $4.23 \pm 0.42$ & $4.38 \pm 0.19$ \\
\hline Aroma floral & $1.85 \pm 0.22$ & $1.84 \pm 0.44$ & $1.87 \pm 0.12$ \\
\hline Aroma grassy & $1.84 \pm 0.38$ & $1.84 \pm 0.27$ & $1.79 \pm 0.35$ \\
\hline Aroma spicy & $2.58 \pm 0.42$ & $2.55 \pm 0.17$ & $2.52 \pm 0.59$ \\
\hline Aroma animal & $1.06 \pm 0.03$ & $1.12 \pm 0.33$ & $1.06 \pm 0.17$ \\
\hline Aroma buttery & $1.08 \pm 0.07$ & $1.12 \pm 0.13$ & $1.09 \pm 0.04$ \\
\hline Aroma toasted & $1.26 \pm 0.03$ & $1.27 \pm 0.34$ & $1.33 \pm 0.22$ \\
\hline Aroma paper & $1.11 \pm 0.39$ & $1.23 \pm 0.74$ & $1.17 \pm 0.36$ \\
\hline Aroma quality & $4.58 \pm 0.17$ & $4.56 \pm 0.34$ & $4.60 \pm 0.06$ \\
\hline Mouthfeel & $4.63 \pm 0.18$ & $4.60 \pm 0.06$ & $4.61 \pm 0.12$ \\
\hline Acidity & $3.91 \pm 0.05$ & $3.86 \pm 0.10$ & $3.86 \pm 0.14$ \\
\hline Tannin intensity & $4.78 \pm 0.04$ & $4.76 \pm 0.15$ & $4.63 \pm 0.18$ \\
\hline Tannin quality & $4.53 \pm 0.31$ & $4.46 \pm 0.07$ & $4.56 \pm 0.23$ \\
\hline Tannin dry & $2.41 \pm 0.47$ & $2.57 \pm 0.29$ & $2.41 \pm 0.55$ \\
\hline Tannin soft & $4.05 \pm 0.36$ & $3.84 \pm 0.60$ & $4.04 \pm 0.65$ \\
\hline Tannin coarse & $3.72 \pm 0.64$ & $3.82 \pm 0.32$ & $3.79 \pm 0.16$ \\
\hline Bitterness & $1.74 \pm 0.30$ & $1.71 \pm 0.25$ & $1.71 \pm 0.44$ \\
\hline General quality & $4.58 \pm 0.18$ & $4.49 \pm 0.17$ & $4.53 \pm 0.05$ \\
\hline
\end{tabular}

described a sensory impact consistent with the chemical analysis.

\section{Conclusion}

A new pilot filtration device was set up at laboratory scale. The wine flows through a filter cake consisting of layers of selective vegetal fibres and kieselguhr. The flow rate is constant due to a peristaltic pump. Technical parameters of the filtration can be kept stable, such as flow rate, temperature and turbidity.

The amount of selective vegetal fibres is a flexible parameter. Tests were done from $0.16 \mathrm{~g}$ to $0.73 \mathrm{~g}$ of selective vegetal fibres added in the filter chamber. The layer of selective vegetal fibre is covered with kieselguhr in order to fill the filtration chamber. The repeatability of the device was evaluated and showed excellent results.

This laboratory pilot filtration device would be a quick and easy tool for winemakers to evaluate the impact of filtration on the wine using selective vegetal fibres in terms of efficiency for pesticide removal, chemical composition, and sensory quality. 


\section{References}

[1] European Food Safety Authority, EFSA Journal. 13(3):4038 (2015)

[2] OIV, International Code of oenological practices, 2.1.9 Treatment with carbon (16/70) (Oeno 3/02), (2016)

[3] OIV, Strategic Plan 2015-2019. Part 4aiii, 6 (2015)
[4] V. Lempereur, C. Louaisil, F. Davaux. BIO Web Conf., 3, 02007 (2014)

[5] OIV, Compendium of International Methods of Analysis of Wines and Musts, OIV-MA-AS323-08 Assay of pesticide residues in wine following extraction using the Quechers method (Oeno 436/2012), (2016) 